\title{
Peri-urban peak hour travel behaviour study using a weigh-in-motion data processing application software
}

\author{
N. Ciont, R. D. Cadar \& M. Iliescu \\ Department of Railways, Roads and Bridges, \\ Technical University of Cluj Napoca, Romania
}

\begin{abstract}
In this paper, the traffic volume processing functions of a designed application software are presented. The road traffic data is collected by a high-speed weighin-motion system, which converts the information into Microsoft Access format, providing separate files for each day. The application software uses the MS Access 2010 database management system, which is based on the Visual Basic for Applications programming language. Based on the processed data, the study analyses the peri-urban travel behaviour at the edge of a major city in Romania. Dedicated software functions were designed to provide daily volumes, weekly averages and peak hour traffic for three daily time intervals. Furthermore, this is done by being differentiated by travel directions, as well as altogether. The study was carried out separately for business days and weekends, using data collected from April 2013 until November 2014. Different travel behaviour trends were observed. Six logarithmic multiple linear regression models were established, describing the peak hour travel trends. The designed software and the obtained results can be used for a wide range of applications.

Keywords: application software, weigh-in-motion, traffic volume, peak hour, travel behaviour trend, linear regression model, logarithmic function.
\end{abstract}

\section{Introduction}

A peri-urban area is defined as a region of transition from urban to rural land uses, located outside urban and regional centres [1]. Generally, at least $40 \%$ of the inhabitants of these units work in the inner city [2]. 
The peak hour of a day is defined as the hourly interval which is characterised by the highest traffic volume [3]. Volume and rate of flow are macroscopic traffic stream parameters which are used to describe traffic as a whole. They represent a quantitative measure used by engineers to better understand, describe and predict traffic flow [4]. Traffic volume is the total number of vehicles passing a carriageway section during a specified time interval, usually an hour, a day or a year [5]. The annual average daily traffic (AADT) is the average daily volume evaluated over the course of a year, at a given location $[3,5]$. On the other hand, the rate of flow represents an equivalent hourly volume at which vehicles travel during a subhourly time interval. Flow rates are variable over the course of an hour. They can be evaluated for different time intervals, such as one, five or fifteen minutes. The peak hour factor (PHF) is evaluated by dividing the traffic volume $(\mathrm{V})$ to the maximum rate of flow $(\mathrm{v})$ within the studied hour (eqn. (1)).

$$
P H F=\frac{V}{v}
$$

The PHF is used to evaluate traffic stream characteristics on a road facility. This is achieved through the concepts of capacity and Level of Service (LOS) [6]. It is also used as a traffic safety predictive tool [7] and to quantify the effects of short time traffic peaking, leading to congestion [8].

By definition, weigh-in-motion (WIM) represents the process of measuring the dynamic tire forces of a moving vehicle and estimating the corresponding tire loads of the static vehicle [9]. Such a system usually includes piezoelectric sensors and inductive loops, as well as data collection equipment. As mentioned by Bottero et al. [10], the technology is an intrusive traffic monitoring device, installed in the pavement wearing course. However, as Slavik [11] emphasised, WIM is a fast, useful and unobtrusive traffic engineering tool, used to continuously measure different traffic parameters without stopping vehicles. The main WIM applications are: pavement design and research, traffic engineering and weight enforcement [12].

Various methods to evaluate the existing traffic conditions and predict the ongoing state of traffic parameters have been developed. They are generally classified as parametric and nonparametric [13]. The former include time-series and Kalman filtering models, whereas the latter contain nonparametric regression methods and neural networks [13]. Chen et al. [14] compared different traffic prediction models, based on data collected using a loop detector located on the SR99 freeway in California. The surveyed models are grouped in six categories:

- Auto Regressive Moving Average (ARMA)/Autoregressive Integrated Moving Average (ARIMA)/Seasonal ARIMA (SARIMA);

- Support Vector Regression (SVR);

- Bayesian networks (BN);

- Feed-Forward Neural Network (FFNN);

- Nearest Neighboring Analysis (NNA);

- Naïve models. 
The results showed that all models, except the Naïve ones, proved to be effective. Portugais and Khanal [15] used the efficient BN model to develop an adaptive speed forecasting method, based on radar based sensing devices and Bluetooth devices in moving vehicles. The proposed model is adaptive to traffic conditions and may be applied to WIM data as well.

The main purpose of this paper is to present the traffic volume processing functions of a designed application software, based on the Visual Basic for Applications (VBA) programming language. The system is currently designed to collect and process the traffic data recorded by a WIM system, but it may also be used for a network of such monitoring devices. A peak-hour travel behaviour study was carried out at the studied location based on the processed traffic data. Multiple linear regression models were established with the purpose of estimating the peak hour travel behaviour.

\section{Traffic data collecting and processing}

\subsection{Data collecting system}

The traffic data analysed in this study was collected using a high-speed weighin-motion (HS-WIM) system. The device has a piezo-loop-piezo (PLP) configuration. It is installed on the European E60 road, at the western edge of the city of Cluj Napoca, Romania. The road has an east-west layout, consisting of a single carriageway with four lanes.

The studied location immediately adjoins the Cluj Napoca urban area (as shown in fig. 1). The E60 road is currently the only functional road link between the inner city to the east and the suburban settlement of Florești, situated to the west. Traffic stream characteristics are heavily influenced by the rapidly growing suburban population (Ciont et al. [16]).

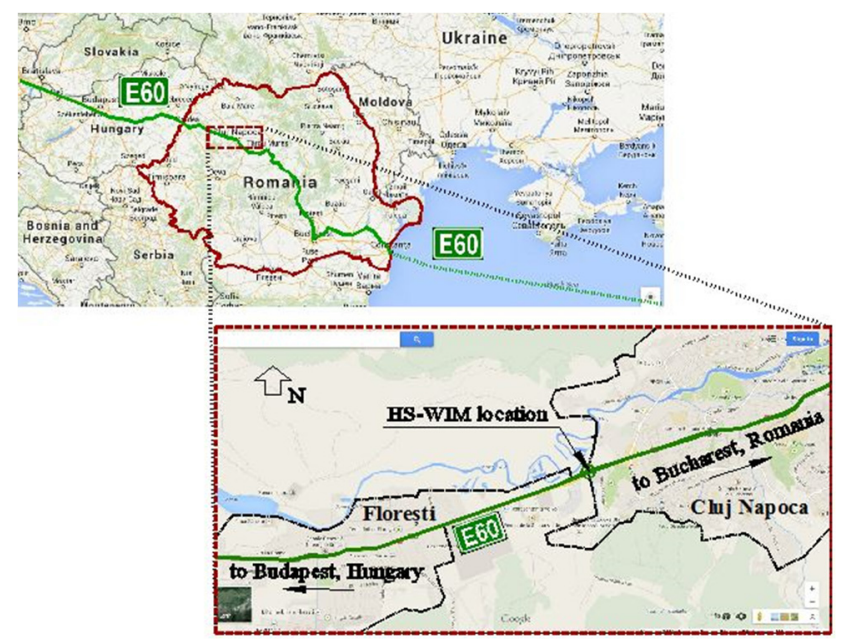

Figure 1: HS-WIM location (source Google Maps). 
The HS-WIM system has been recording traffic data since 25 April 2013. The information is stored on an SRAM memory unit and may be downloaded on a PC. The system converts the collected traffic data into Microsoft Access (MS Access) files, providing separate files for each day.

\subsection{Data processing application software}

Each HS-WIM MS Access file includes various useful traffic information. However, this implies that the files are quite large (20-26 MB per daily file), leading to very high computer memory usage. Furthermore, data processing is time-consuming, especially for long monitoring periods. Converting the daily MS Access files into MS Excel format is not an option, due to worksheet limits. Without a suitable processing tool, the collected traffic data becomes unusable.

An application software was designed to process the input HS-WIM database files. The information is analysed and processed using the MS Access 2010 database management system, which offers a user-friendly interface. The system is based on the Visual Basic for Applications (VBA) programming language. One of its advantages is that the user does not need to install the MS Office suite, as free of charge runtime environments (Plug and Play) are available.

The main purpose of the designed application is to provide a useful tool for the processing, analysis and reporting of the recorded traffic parameters. The basic software flowchart (shown in fig. 2), begins by loading the HS-WIM database files. The application performs several validity checks, until the database is cleared of invalid data (e.g. nonexistent lanes, wrong direction etc.). Usually, there are a limited number of erroneous recordings. As soon as the checks are passed, the software processes the input data, according to the user function request. A selective database browsing algorithm was implemented, which improves time consumption and memory usage. The results are initially displayed in MS Access format, but the application also provides the option to export them to MS Excel.

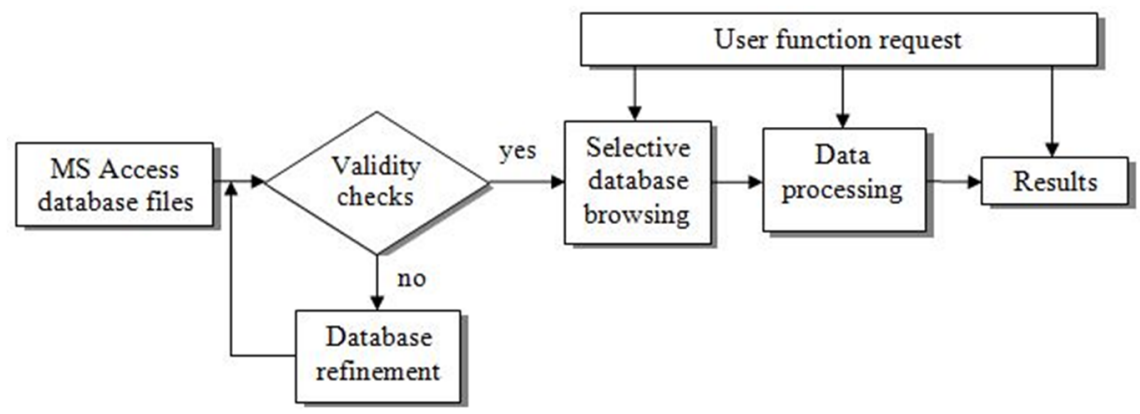

Figure 2: $\quad$ Software flowchart. 


\subsection{Software functionality}

The designed application software includes several functions used to evaluate a wide variety of traffic stream characteristics. All of them begin by selecting the desired study period (as shown in fig. 3). File loading is done by pressing the appropriate button. By default, the software appends the database files loaded at a later moment to the ones already existing in the memory, unless the clearing checkbox is ticked.

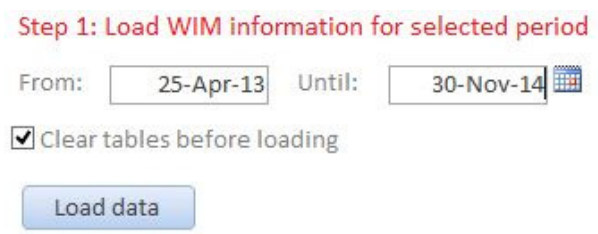

Figure 3: Data loading window.

The designed application provides the following results on traffic volumes, rates of flow and peak hours:

- daily and total volumes for the selected time period;

- AADT for the defined vehicle groups and per total;

- daily volumes, weekly averages and monthly averages, for all vehicles and for heavy vehicles;

- daily and weekly average volumes, for the defined vehicle groups;

- traffic distribution on each lane;

- hourly volumes, daily peak hours and PHFs, differentiated by travel direction, as well as altogether.

Heavy vehicles are defined as those vehicles which have a gross weight of more than $3500 \mathrm{~kg}$.

To provide a useful and suggestive peak hours study, the designed software divides the 24 hours of a day into five intervals: 0:00:00-4:59:59 (night), 5:00:00-9:59:59 (morning), 10:00:00-14:59:59 (noon), 15:00:00-19:59:59 (afternoon), 20:00:00-23:59:59 (evening). The studied road sector is situated in a peri-urban area, intensely used by commuters. This aspect determined the evaluation of the morning, noon and afternoon peak hours. The application allowed the analysis to be carried out separately for working days (Monday to Friday) and for weekends. It was considered that hourly intervals during the evening and night are not relevant for the analysed travel behaviour.

\section{Results}

The HS-WIM traffic data used in this study was collected between 25 April 2013 and 30 November 2014. As the studied location immediately adjoins the Cluj Napoca urban area, the analysis was carried out differentiated by travel direction. 
It was also considered relevant to analyse the travel behaviour separately for business days and weekends.

\subsection{Traffic volume and peak hours}

Using the specialised application function, the average hourly volumes were obtained. Each value was calculated as an arithmetic mean of the volumes counted during that specific hour. The obtained figures (fig. 4) clearly show that the studied facility is situated in a peri-urban area intensely used by commuters. On business days, most vehicles are heading east in the morning, towards the inner city, and in the opposite direction during the afternoon, towards the suburban shopping and residential areas (fig. 1).

This tendency changes on weekends. As shown in fig. 5, traffic heading east and west have rather similar variations, peaking at noon and during the afternoon.

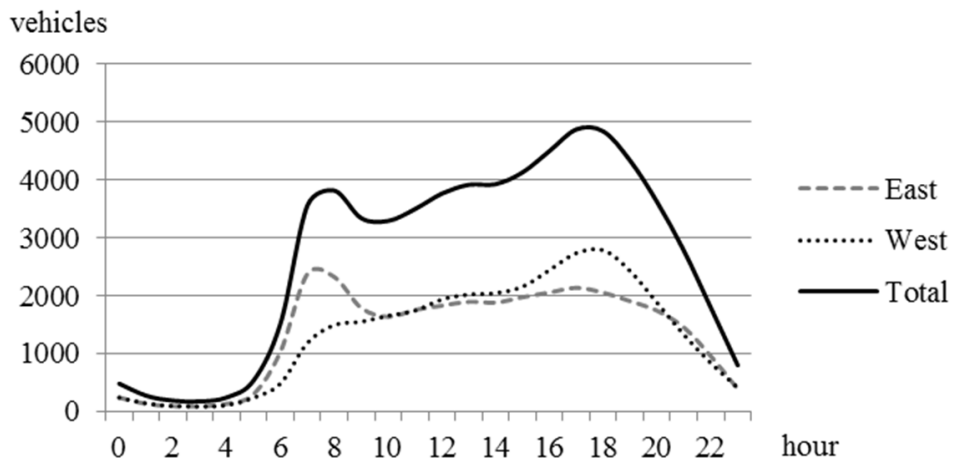

Figure 4: Average hourly volumes, business days.

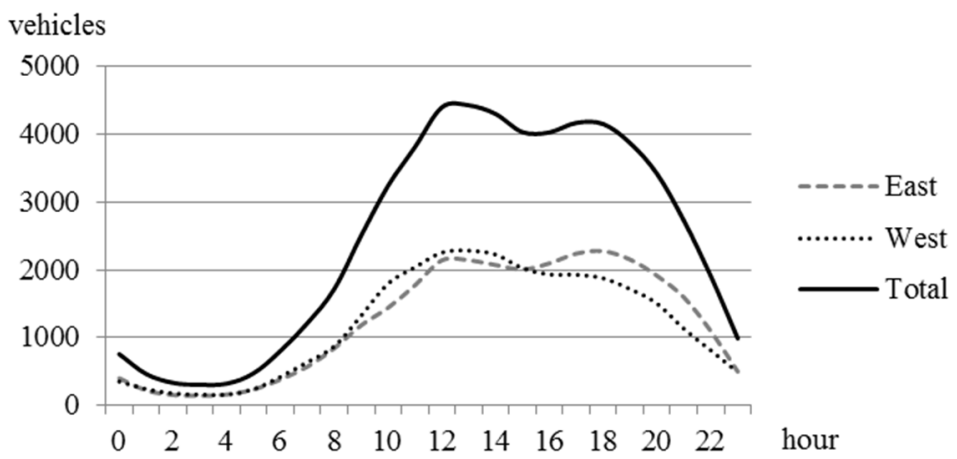

Figure 5: Average hourly volumes, weekends. 
The designed application evaluates five daily peak hours, differentiated by travel direction and altogether as well. In this paper, the morning, noon and afternoon intervals were considered relevant. The peak hour occurrence obtained using the application software for working days and weekends is shown in fig. 6, fig. 7 and fig. 8.
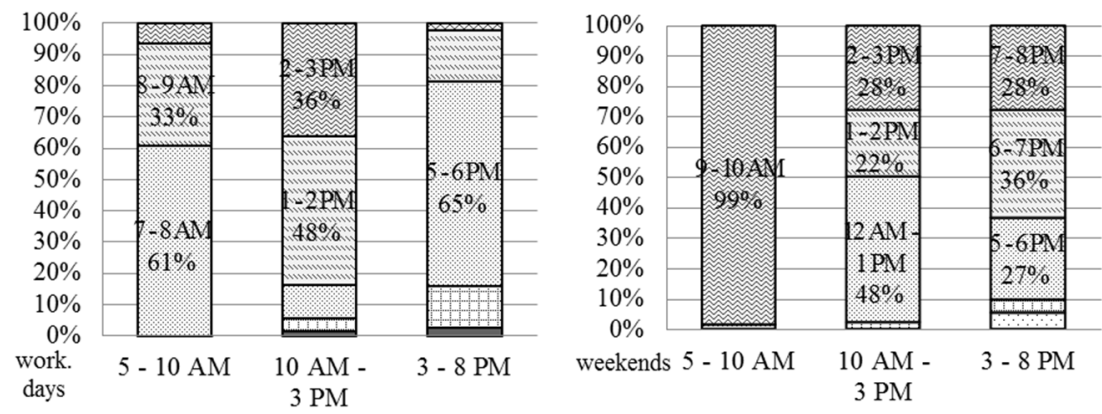

Figure 6: Peak hour occurrence, eastbound.
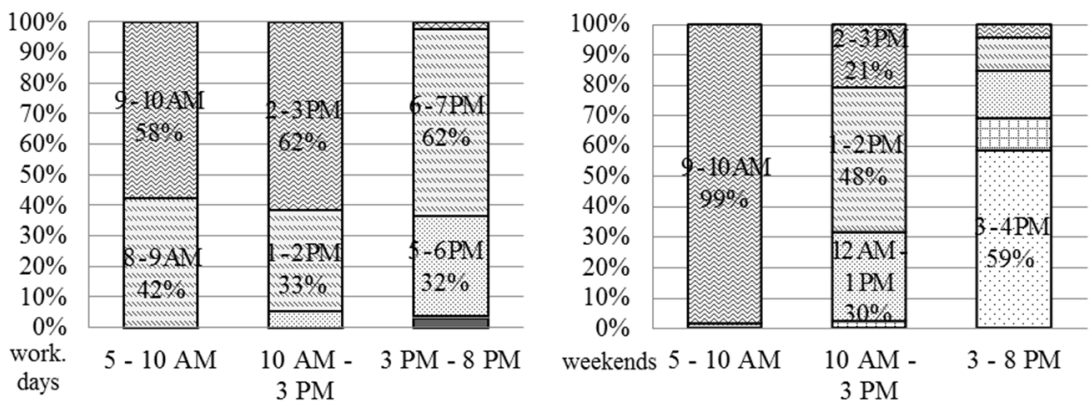

Figure 7: Peak hour occurrence, westbound.
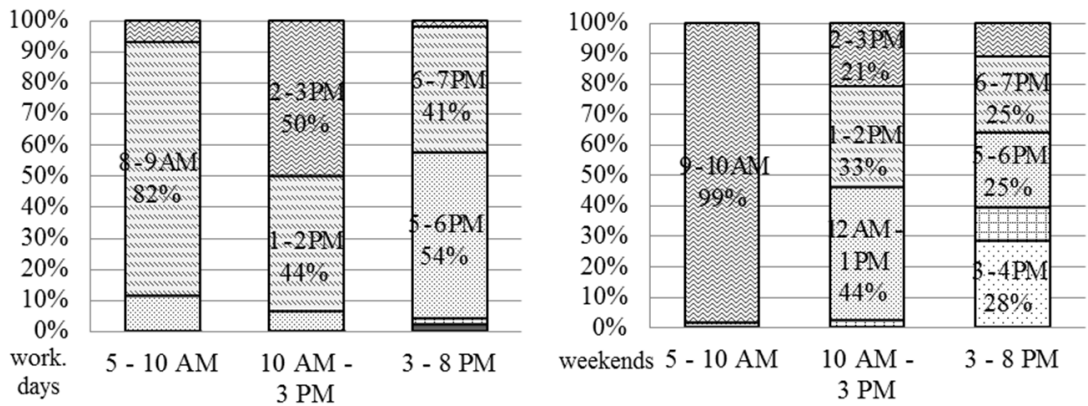

Figure 8: Peak hour occurrence, total. 


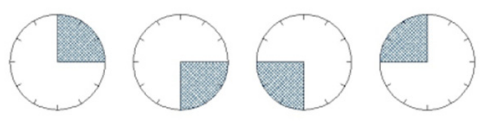

Figure 9: Main quarter-hours.

For each peak hour, the software identifies the busiest main quarter-hour (fig. 9). However, it is not certain that the peak 15-minute interval is one of the four main quarter-hours. The Highway Capacity Manual [5] recommends evaluating the maximum rate of flow based on the busiest 15 minutes of the considered design or peak hour. Other sub-hourly intervals may also be used [3]. The designed software identifies the peak five and 15-minute intervals within the peak hours and uses the corresponding rates of flow to evaluate the PHF. This is a useful feature of the application. Nevertheless, Ciont et al. [17] found that evaluating flow rates based on the main quarter-hours provides the highest PHF values, similar to the ones recommended by Romanian and international standards [5]. This is also the approach used in this study to identify the busiest quarter-hours in the studied area.

The major advantage of the designed application software is its capability to process large amounts of HS-WIM data, in order to provide essential traffic information. The busiest main quarter-hours identified for every peak hour are shown in table 1 for working days and table 2 for weekends, respectively.

Table 1: $\quad$ Busiest main quarter-hours, business days.

\begin{tabular}{|c|c|c|c|c|c|}
\hline \multirow{3}{*}{ Direction } & Hour Interval & $\begin{array}{c}\text { Peak } \\
\text { hour }\end{array}$ & $\begin{array}{c}\text { Peak hour } \\
\text { occurence } \\
{[\%]}\end{array}$ & $\begin{array}{c}\text { Peak } \\
\text { quarter- } \\
\text { hour }\end{array}$ & $\begin{array}{c}\text { Peak quarter- } \\
\text { hour occurence } \\
{[\%]}\end{array}$ \\
\hline \multirow{3}{*}{ east } & 5 AM-10 AM & 7 AM & 61 & $30-45$ & 44 \\
\cline { 2 - 6 } & 10 AM-3 PM & 1 PM & 47 & $15-30$ & 31 \\
\cline { 2 - 6 } & 3 PM-8 PM & 5 PM & 65 & $15-30$ & 31 \\
\hline \multirow{3}{*}{ west } & 5 AM-10 AM & 9 AM & 58 & $45-60$ & 80 \\
\cline { 2 - 6 } & 10 AM-3 PM & 2 PM & 61 & $30-45$ & 32 \\
\cline { 2 - 6 } total & 3 PM-8 PM & 6 PM & 61 & $15-30$ & 32 \\
\hline \multirow{3}{*}{} & $5 \mathrm{AM}-10$ AM & 8 AM & 82 & $0-15$ & 51 \\
\cline { 2 - 6 } & $10 \mathrm{AM}-3$ PM & 2 PM & 50 & $30-45$ & 31 \\
\cline { 2 - 6 } & 3 PM-8 PM & 5 PM & 54 & $15-30$ & 32 \\
\hline
\end{tabular}

\subsection{Travel behaviour trends}

The main trend observed was that most trips made during business days are concentrated between the following intervals: 7 AM-9 AM (93\%), 1 PM-3 PM (94\%) and 5 PM-7 PM (95\%) (Figure 8). On weekends, however, peak traffic volumes are rather spread during the noon and afternoon. Nevertheless, in the morning, the busiest hour is from 9 to 10 o clock in $99 \%$ of cases.

On working days, the busiest morning quarter-hour is from 8:00 to 8:15 in $51 \%$ of cases (table 1). This is the time when commuters are heading east. In the afternoon, volume is peaking between 5:15 and 6:30 PM. 
Table 2: $\quad$ Busiest main quarter-hours, weekends.

\begin{tabular}{|c|c|c|c|c|c|}
\hline \multirow{3}{*}{ Direction } & Hour Interval & $\begin{array}{c}\text { Peak } \\
\text { hour }\end{array}$ & $\begin{array}{c}\text { Peak hour } \\
\text { occurence } \\
{[\%]}\end{array}$ & $\begin{array}{c}\text { Peak } \\
\text { quarter- } \\
\text { hour }\end{array}$ & $\begin{array}{c}\text { Peak quarter- } \\
\text { hour occurence } \\
{[\%]}\end{array}$ \\
\hline \multirow{3}{*}{ east } & $5 \mathrm{AM}-10 \mathrm{AM}$ & $9 \mathrm{AM}$ & 99 & $45-60$ & 69 \\
\cline { 2 - 6 } & $10 \mathrm{AM}-3 \mathrm{PM}$ & $12 \mathrm{PM}$ & 48 & $45-60$ & 35 \\
\cline { 2 - 6 } & $3 \mathrm{PM}-8 \mathrm{PM}$ & $6 \mathrm{PM}$ & 36 & $45-60$ & 32 \\
\hline \multirow{3}{*}{ west } & $5 \mathrm{AM}-10 \mathrm{AM}$ & $9 \mathrm{AM}$ & 99 & $45-60$ & 80 \\
\cline { 2 - 6 } & $10 \mathrm{AM}-3 \mathrm{PM}$ & $1 \mathrm{PM}$ & 48 & $15-30$ & 42 \\
\cline { 2 - 6 } & $3 \mathrm{PM}-8 \mathrm{PM}$ & $3 \mathrm{PM}$ & 59 & $0-15$ & 47 \\
\hline \multirow{3}{*}{ total } & $5 \mathrm{AM}-10 \mathrm{AM}$ & $9 \mathrm{AM}$ & 99 & $45-60$ & 90 \\
\cline { 2 - 6 } & $10 \mathrm{AM}-3 \mathrm{PM}$ & $12 \mathrm{PM}$ & 44 & $45-60$ & 35 \\
\cline { 2 - 6 } & $3 \mathrm{PM}-8 \mathrm{PM}$ & $3 \mathrm{PM}$ & 28 & $0-15$ & 51 \\
\hline
\end{tabular}

The daily peak hour volume variation for the studied period may be represented as shown in fig. 10. Similar graphs are obtained for traffic heading east or west, at noon or in the afternoon.

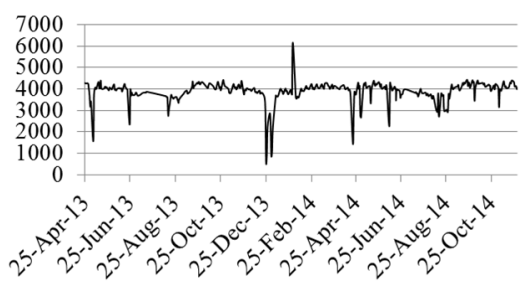

business days, total volumes, morning

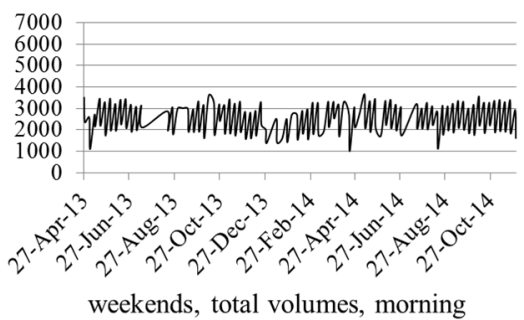

weekends, total volumes, morning

Figure 10: Daily peak hour volumes, morning.

Based on the peak hour processed data, multiple linear regression models were established for the recorded total traffic volumes. These methods may be applied to any function which is linear in the coefficients. After studying different models, it was found that a logarithmic function best describes the peak hour travel behaviour trend. The general formula is shown in eqn. (2).

$$
f(x)=A \cdot \ln (x)+B
$$

The variable is the date, converted into number format by MS Excel. The regression coefficients A and B were evaluated using MS Excel's LINEST function, based on the recorded daily traffic volumes processed using the designed application software. All recorded days were included in the calculus. Given the obtained graphs, the measure of correlation is close to nil. However, the purpose of establishing regression models was to create a tool for estimating peak hour travel behaviour trends in general. As shown by Chen et al. [14], this may notably improve prediction performance. The obtained peak hour regression models for the total processed traffic volumes are shown in table 3 . 
Table 3: Peak hour multiple linear regression models.

\begin{tabular}{|c|c|c|}
\hline Hour interval & Business days & Weekends \\
\hline morning & $\mathrm{f}(\mathrm{x})=11512 \cdot \ln (\mathrm{x})-118588$ & $\mathrm{f}(\mathrm{x})=586 \cdot \ln (\mathrm{x})-3713$ \\
\hline noon & $\mathrm{f}(\mathrm{x})=1965 \cdot \ln (\mathrm{x})-16913$ & $\mathrm{f}(\mathrm{x})=19339 \cdot \ln (\mathrm{x})-201173$ \\
\hline afternoon & $\mathrm{f}(\mathrm{x})=4518 \cdot \ln (\mathrm{x})-43079$ & $\mathrm{f}(\mathrm{x})=34631 \cdot \ln (\mathrm{x})-364056$ \\
\hline
\end{tabular}

\section{Conclusions}

A designed application software used to process road traffic data was presented. The information is recorded by a HS-WIM system, installed at the western edge of the city of Cluj Napoca, Romania. The application is based on the VBA programming language. Among other relevant parameters, it provides results on daily and weekly traffic volumes, AADT and peak hours.

For this analysis, the data collected between 25 April 2013 and 30 November 2014 was used. The studied days were divided into business days and weekends, considering three intervals for the peak hour determination: morning, noon and afternoon.

The results confirmed that the studied section is situated in a peri-urban area intensely used by commuters. Peak hour occurrence and the busiest quarterhours were evaluated, differentiated by travel direction, as well as altogether. Using the peak hour volumes, six logarithmic multiple linear regression models were established, for each considered interval.

The results can be used to estimate travel behaviour on similar facilities. The regression models may provide peak hour traffic volumes used for designing new facilities or expanding existing ones. Other uses include improving prediction accuracy and establishing growth factors. The designed application software allows similar studies to be conducted separately for different vehicle categories.

\section{Acknowledgements}

This paper is supported by the Sectoral Operational Programme Human Resources Development POSDRU/159/1.5/S/137516 financed from the European Social Fund and by the Romanian Government.

\section{References}

[1] International conference on peri-urban landscapes: water, food and environmental security; Peri-urban 2014, www.periurban14.org

[2] INSEE, www.insee.fr

[3] Roess, R.P., Prassas, E.S. \& McShane, W.R., Traffic Engineering, Third Edition, Pearson Prentice Hall, Upper Saddle River, New Jersey, 2004. 
[4] Abdulhai, B. \& Kattan, L., Traffic engineering analysis (Chapter 6). Handbook of Transportation Engineering, ed. M. Kutz, McGraw-Hill Professional, pp. 6.3-6.72, 2004.

[5] Transportation Research Board, Highway Capacity Manual Fifth Edition, Washington DC, 2010.

[6] Bassan, S., Modeling of Peak Hour Factor on Highways and Arterials. KSCE Journal of Civil Engineering, 17(1), pp. 224-232, 2013.

[7] Milton, J. \& Mannering F., The relationship among highway geometrics, traffic-related elements and motor-vehicle accident frequencies. Transportation, 25, pp. 395-413, 1998.

[8] Lan, C.J. \& Abia, S.D., Determining Peak Hour Factor for Capacity Analysis, Journal of Transportation Engineering, 137(8), pp. 520-526, 2011.

[9] ASTM E1318-02, Standard Specification for Highway Weigh-in-Motion (WIM) Systems with User Requirements and Test Methods. ASTM International, West Conshohocken, Pennsylvania, 2002.

[10] Bottero, M., Dalla Chiara, B. \& Deflorio, F.P., Wireless sensor networks for traffic monitoring in a logistic centre. Transportation Research Part C, Elsevier, 26(2013), pp. 99-124.

[11] Slavik, M., Weigh-in-motion: years of South African experience. Journal of the South African Institution of Civil Engineering, 49(1), paper 617, pp. 11-16, 2007.

[12] Wang, J. \& Wu, M., An Overview of Research on Weigh-in-motion System. Proc. of the $5^{\text {th }}$ World Congress on Intelligent Control and Automation, Hangzhou, P.R. China, pp. 5241-5244, 2004.

[13] Comert, G. \& Bezuglov, A., An Online Change-Point-Based Model for Traffic Parameter Prediction. IEEE Transactions on Intelligent Transportation Systems, 14(3), pp. 1360-1369, 2013.

[14] Chen, C., Wang, Y., Hu, J. \& Zhang, Z., The retrieval of intra-day trend and its influence on traffic prediction. Transportation Research Part $C$, Elsevier, 22(2012), pp. 103-118.

[15] Portugais, B. \& Khanal, M., Adaptive traffic speed estimation. Procedia Computer Science, Elsevier, 32(2014), pp. 356-363.

[16] Ciont, N., Iliescu, M. \& Cadar, R.D., Comparative studies regarding traffic flow improvement scenarios using software modelling and real measured data, Proc. of the $3^{\text {rd }}$ Int. Conf. on Road and Rail Infrastructures, ed. S. Lakušić, Zagreb, pp. 229-235, 2014.

[17] Ciont, N., Cadar, R.D., Iliescu, M. \& Laslău, D.A., Interactive application for the evaluation of the Peak Hour Factor using weigh-in-motion traffic data. University Politehnica of Bucharest Scientific Bulletin Series C, 77(1), pp. 121-128, 2015. 